\title{
Pedigree selection for number of bolls/plant in two segregating populations of Egyptian cotton (Gossypium barbadense L.)
}

\author{
Ali, M.A. ${ }^{1}$, M.S. Hassan ${ }^{1}$, A.A. Mohamed ${ }^{2}$ and A.A. Abbas ${ }^{1}$ \\ ${ }^{I}$ Department of Agronomy, Faculty of Agriculture, South Valley University, Qena, Egypt. \\ ${ }^{2}$ Cotton Research Institute, Agriculture Research Center, Giza, Egypt.
}

\begin{abstract}
This work aimed to study the efficiency of pedigree selection for number of bolls/plant to isolate superior families in two segregating population of Egyptian cotton (Giza-90 $\times$ Giza-86) and (Giza-95 $\times$ Giza-80) in the $\mathrm{F}_{2}-\mathrm{F}_{4^{-}}$ generations. The experiments were conducted at South Valley University Experimental Farm, Qena, Egypt during summer seasons 2018 to 2020 . Differences among the $\mathrm{F}_{4}$-selected families were highly significant for the selection criterion; number of bolls/plant and all correlated traits after two cycles of selection in both populations. The genetic variability retained after two cycles of selection was greater and sufficient for further cycles of selection of the selection criterion; number of bolls/plant in both populations. However, all studied correlated traits showed greater genotypic variability in both populations after two cycles of selection. After two cycles of selection, number of bolls/plant increased by 10.67 and $12.41 \%$ in population I and 10.58 and $17.26 \%$ in population II from the better parent and the bulk sample, respectively. Selection for number of bolls/plant was accompanied by favourable decrease in days to first flower in both populations. However, desirable increase for most correlated traits i.e., boll weight, seed cotton yield/plant, lint yield/plant and lint percentage in both populations. Two families; No. 96 and 178 in population I and family No. 60 in population II could be considered the best selected families resulted from selection for number of bolls/plant. Pedigree selection for number of bolls/plant was effective in isolating genotypes for high number of bolls.
\end{abstract}

Keywords: Pedigree selection, Egyptian cotton, genetic variability and number of bolls.

\section{Introduction}

Egyptian cotton (G.barbadense L.) is considered the best fiber crop not only in Egypt but also all over the world. The principal objectives to all cotton breeders around the world are improvement of early mature, high yielding and high quality cotton varieties. Therefore, plant breeders are continuously searching for a more effective and efficient selection method. Effective breeding program depends upon the

\footnotetext{
*Corresponding author: M. A. Ali,

Email: mohamed agr@yahoo.com

Received: June 1, 2021; Accepted: June 26, 2021;

Published online: July 30, 2021.

(C) Published by South Valley University.

This is an open access article licensed under (C)(2)
}

variation present in the gene pool for the yield enhancing traits. Selection is effective when magnitude of variability in the breeding although several selection methods were used for improving several traits in cotton, pedigree selection method has become the most popular of plant breeding procedures. Most of Egyptian cotton varieties were produced through this method. According to FAOSTAT (2019), the total area for cotton cultivation was 100000 hectare, while the production was estimated at 305000 tonnes and yield per ha 3.5 metric tonnes in Egypt. Therefore, the new trend in Egypt is to increase the cultivated area of the cotton in newly reclaimed lands by developing new varieties that tolerate to harsh conditions such as drought, heat, salinity and low soil 
fertility. The coefficient of variation indicates only the extent of variability existing for various traits but does not give any information about the heritable portion of it. Therefore, heritability accompanied by estimates of genetic advance and genetic advance as percent mean were also estimated. Heritability provides no indication about the genetic progress that would result from selection. However, at a fixed selection pressure, the amount of advance varies with magnitude of heritability. Genetic advance in a population cannot be predicted from heritability alone, the genetic gain for specific selection pressure has to be worked out (Basbag and Oktay, 2004 and Alkuddsi et al., 2013). Highly significant differences among selected families for number of balls/plant and correlated traits i.e., seed cotton yield/plant, lint yield/plant, boll weight and seed index were reported in previous studies (Khan et al., 2009; Soomro et al., 2010; Mahdy et al., 2013 and Ahsan et al., 2015). Several studies indicated that pedigree method succeeded in improving number of bolls/plant in cotton (Ahuja et al., 2004; Khan et al., 2009; Soomro et al., 2010; El-Zanaty et al., 2011; Mahdy et al., 2013b and Ahsan et al., 2015). Ahuja et al. (2004), Mahrous (2008), Khan et al. (2009), Soomro et al. (2010), Mahdy et al. (2013b), Ahsan et al. (2015), Mahrous and Soliman (2017), Okaz et al. (2017), Mahrous (2018) and Abd-El-Sameea et al. (2020) reported that high estimates of genetic coefficient of variation, heritability and genetic advance were observed for seed cotton yield per plant, number of bolls per plant, ball weight and plant height. On the other hand, the broad sense heritability, genetic advance as percent of mean were low for number of bolls/plant (3.01 and $3.68 \%$, respectively). In addition, the phenotypic variance was 31.38, genotypic variance was 4.53 and the GCV and PCV values for number of bolls/plant were low to moderate (Alkuddsi et al., 2013). The present work aimed to study the efficiency of pedigree selection in improving number of bolls/plant to isolate superior families and consequently improving seed cotton in yield.

\section{Materials and Methods}

\subsection{Experimental site}

Two experiments were conducted at Experimental Farm of Faculty Agricultural of South Valley University, Qena, Egypt during 2018, 2019 and 2020 summer seasons. Table 1 shows some physical and chemical characteristics of a representative soil sample from the field experimental site.

\subsection{Experimental materials}

Two $\mathrm{F}_{2}$-populations of cotton as basic materials initiated from crosses between four Egyptian cotton varieties ( $G$. barbadense L.) were used. The first (Pop I) and second (Pop II) populations developed from the crosses (Giza-90 × Giza-86) and (Giza-95 $\times$ Giza-80), respectively.

\subsection{Base populations ( $F_{2}$-generations)}

In 2018 summer season, seeds of $F_{2}$ from each population were sown separately in a nonreplicated trail; each in 40 rows, $4 \mathrm{~m}$ long, 60 $\mathrm{cm}$ a wide and $40 \mathrm{~cm}$ between hills within a row. The parents were sown in individual plots for each population. After full emergence, the hills were thinned to one plant/hill after three weeks from sowing. All other cultural practices were applied as recommended for cotton production in the three seasons. Data were registered on 268 and 232 random guarded plants from the first and second populations, respectively. For each population, the following characters were recorded on individual guarded plants of each plot: days to first flower, earliness index, number of bolls/plants, boll weight, seed-cotton yield/plant, lint yield/plant, lint percentage and seed index. 
Table 1. Some physical and chemical properties of the experimental site in 2018, 2019 and 2020.

\begin{tabular}{|c|c|c|c|c|}
\hline \multirow{2}{*}{\multicolumn{2}{|c|}{ Soil property }} & \multicolumn{3}{|c|}{ Seasons } \\
\hline & & 2018 & 2019 & 2020 \\
\hline \multicolumn{2}{|c|}{ Sand $(\%)$} & 66.70 & 87.00 & 84.02 \\
\hline \multicolumn{2}{|c|}{ Silt (\%) } & 21.30 & 8.00 & 7.98 \\
\hline \multicolumn{2}{|c|}{ Clay (\%) } & 12 & 5 & 8 \\
\hline \multicolumn{2}{|c|}{ Soil texture } & $\begin{array}{l}\text { Sandy } \\
\text { loam }\end{array}$ & Sandy & Sandy \\
\hline \multicolumn{2}{|c|}{$\mathrm{pH}(1: 1)$} & 7.93 & 8.18 & 8.8 \\
\hline \multicolumn{2}{|c|}{$\begin{array}{l}\text { Organic matter } \\
(\%)\end{array}$} & 0.3 & 0.4 & 0.4 \\
\hline \multicolumn{2}{|c|}{$\mathrm{EC}(\mathrm{ds} \mathrm{m}-1)$} & 9.95 & 2.07 & 7.5 \\
\hline \multicolumn{2}{|c|}{$\mathrm{CaCO} 3(\%)$} & 5.8 & 11.88 & 7.4 \\
\hline \multirow{7}{*}{ 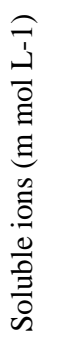 } & $\mathrm{SO}^{--4}$ & 52.3 & 55.4 & 55.4 \\
\hline & $\mathrm{K}^{+}$ & 0.80 & 0.28 & 0.28 \\
\hline & $\mathrm{Ca}^{++}$ & 11.5 & 2.0 & 2.0 \\
\hline & $\mathrm{Mg}^{++}$ & 11.3 & 1.5 & 1.5 \\
\hline & $\mathrm{HCO}^{-3}$ & 20.00 & 10.0 & 10.0 \\
\hline & $\mathrm{Cl}^{-}$ & 27.50 & 33.0 & 33.0 \\
\hline & $\mathrm{SO}^{--4}$ & 23.2 & 6.9 & 6.9 \\
\hline
\end{tabular}

Two pickings were done on single plants at the end of growing season. For each population, five seeds from each of the 268 plants (Pop I) and from each of the 232 plants (Pop. II) were bulked to give an unselected bulk sample. From each population, seeds of the best 20 plants in number of bolls/plant as selection criterion were saved.

\section{4. $F_{3}$-generation}

In 2019 summer season, the $20 \mathrm{~F}_{3}$-families from each population along with the unselected bulk sample and the two parents were grown in a randomized complete block design (RCBD) with three replicates for each population independently. The plot size was one row as in the previous season. The traits were registered as in the previous season as an average of five guarded plants from each family. After harvest, the best plant from each of the best ten families for number of bolls/plant as selection criterion were saved for the following generation. Seeds of the unselected bulk sample were bulked without selection.

\section{5. $\mathrm{F}_{4}$ generation}

In 2020 summer season, the same 10 selected families for number of bolls/plant as selection criterion along with the parents and the unselected bulk sample were grown as in the previous season. Observations were recorded on five guarded plants from each family.

\subsection{Statistical analysis}

Two separate analyses of variance were done according to Snedecor and Cochran (1980) by MSTAT-C computer program in a randomized complete block design. The first includes the entries (10 selected families along with the bulk samples and parents to measure the variability and the significance of the observed gain. The second included the selected families only to calculate phenotypic (PCV), genotypic (GCV) coefficients of variability and heritability in broad sense. The phenotypic $\left(\sigma^{2} p\right)$ and genotypic $\left(\sigma^{2} \mathrm{~g}\right)$ variances were calculated according to Al-Jibouri et al. (1958). Heritability in broad sense was estimated as $(H)=\left(\sigma^{2} g / \sigma^{2} p\right)$ $\times 100$ according to Walker (1960). The phenotypic (PCV\%) and genotypic (GCV\%) coefficients of variability were estimated using the formula developed by Burton (1952). Comparisons between means were calculated by using revised L.S.D (El-Rawi and Khalafalla, 1980) as follow:

Where, L.S.D = Least significant differences between random sample, the best parent, and mean of each selected family was calculated as:

$$
\mathrm{RLSD}=\dot{t}_{\alpha}^{\prime} \times \sqrt{\frac{2 M S e}{r}}
$$

L.S.D = Least significant differences between random sample, the best parent, and mean of all selected families was calculated as: 
$\mathrm{RLSD}=\dot{t}^{\prime} \times \sqrt{\frac{M S e}{r}}+\sqrt{\frac{M S e}{r f}}$

Where, $t$ ' from minimum - average-risk table. f; number of the selected families

- Deviation of the direct and correlated response to selection in percentage from the unselected bulk sample and the better parent was measured by using L.S.D. test.

\section{RESULTS AND DISCUSSION}

\subsection{Description of the $F_{2}$-populations}

3.1.1. Average, phenotypic coefficient of variation (CV\%), heritability in broad sense (H\%) and expected genetic advance from the mean (LG/Mean (\%))

The characteristic of the two populations (Table 2) exhibited that the average number of bolls/plant of pop. I was lower (30.06) than better parent Giza-90 (36.59) and higher than the other parent Giza-86 (20.50). This indicates that partial dominance towards the better parent Giza-90. High CV\% (41.90\%) was obtained for pop. I compared to moderate CV\% (11.15\%) for pop. I compared to moderate CV\% (11.15\%) for Giza-90 and low CV\% (3.44\%) for Giza-86. Therefore, high estimates of broad sense heritability (99.79\%) and very large expected genetic advance in percentage of the mean (86.14\%) were observed. In pop. II (Table 2), the average number of bolls/plant was 25.84 compared to 31.33 for Giza-95 and 21.50 for Giza-80. The phenotypic variation (CV\%) of number of bolls/plant for the two parents was very low compared to high CV\% (20.36\%) for pop II. Hence, very high estimates of broad sense heritability of 98.19 and expected genetic advance as percentage of the mean of 40.42 were observed.

\subsubsection{Correlation study}

The correlation coefficients (Table 3) were positive and highly significant between number of bolls/plant with each of boll weight, seed cotton yield/plant, lint yield/plant, lint percentage and seed index in both populations except boll weight in population I was negative and insignificant. Consequently, this observation suggested that selection practiced for the improvement of the number of bolls/plant would automatically improve these characters. On the other hand, number of bolls/plant demonstrated negative and highly significant correlation with each of days to first flower and earliness index. These results were agreement with those obtained by Abo-Sen (2001), Mahdy et al. (2001), Ahuja et al. (2004), Iqbal et al. (2006), Khan et al. (2009), Mahdy et al. (2017), Okaz et al. (2017), Nikhil et al. (2018), Nawaz et al. (2019) and Chapepa et al. (2020).

\subsection{Pedigree selection for number of bolls/plant; variability and heritability estimates}

\subsubsection{Analysis of variance}

Differences among genotypes and $\mathrm{F}_{4}$-families were significant $(p<0.01)$ for selection criterion; number of balls/plant and correlated traits i.e., days to first flower, earliness index, boll weight, seed cotton yield/plant, lint yield/plant, lint percentage and seed index in pop I and II (Table 4). This indicates that the existence of sufficient variability for further improvement. These results agreed with those reported by Khan et al. (2009), Soomro et al. (2010), Mahdy et al. (2013b) and Ahsan et al. (2015). 
Table 2. Means, phenotypic coefficient of variation (CV\%), heritability in broad sense $(\mathrm{H} \%)$ and expected genetic advance from the mean $(\Delta \mathrm{G} / \mathrm{Mean}(\%))$ of the two base populations I and II $\left(\mathrm{F}_{2}\right)$ and its parents of the studied traits; season 2018.

\begin{tabular}{|c|c|c|c|c|c|c|c|c|c|}
\hline Populations & Variable & DFF & EI & $\mathrm{NOB} / \mathrm{P}$ & $\mathrm{BW}$ & $\mathrm{SCY} / \mathrm{P}$ & $\mathrm{LY} / \mathrm{P}$ & LP & SI \\
\hline \multirow{4}{*}{ I } & Mean \pm SE & $66.40 \pm 0.51$ & $66.02 \pm 0.87$ & $30.06 \pm 0.42$ & $2.47 \pm 0.002$ & $171.12 \pm 5.09$ & $59.71 \pm 1.81$ & $34.47 \pm 0.18$ & $8.15 \pm 0.05$ \\
\hline & $\mathrm{CV} \%$ & 12.96 & 21.46 & 41.90 & 22.18 & 82.55 & 48.69 & 8.77 & 10.86 \\
\hline & $\mathrm{H} \%$ & 83.93 & 83.54 & 99.79 & 96.67 & 98.91 & 97.92 & 87.18 & 93.55 \\
\hline & $\Delta \mathrm{G}$ & 14.43 & 24.38 & 25.89 & 1.10 & 169.78 & 59.77 & 5.17 & 1.59 \\
\hline \multirow{3}{*}{$\mathrm{P}_{1}$ (Giza 90) } & $\Delta \mathrm{G} / \mathrm{Mean}(\%)$ & 22.41 & 36.93 & 86.14 & 44.36 & 99.22 & 100.11 & 15.00 & 19.51 \\
\hline & Mean \pm SE & $65.68 \pm 1.16$ & $78.03 \pm 2.02$ & $36.59 \pm 0.48$ & $2.31 \pm 0.04$ & $38.39 \pm 0.85$ & $13.27 \pm 0.32$ & $36.23 \pm 0.27$ & $8.89 \pm 0.22$ \\
\hline & $\mathrm{CV} \%$ & 6.82 & 10.03 & 11.15 & 6.55 & 8.56 & 4.42 & 2.85 & 9.67 \\
\hline \multirow[t]{3}{*}{$\mathrm{P}_{2}($ Giza 86$)$} & Mean \pm SE & $70.90 \pm 1.28$ & $69.06 \pm 2.06$ & $20.50 \pm 0.20$ & $2.27 \pm 0.05$ & $30.24 \pm 0.94$ & $10.07 \pm 0.35$ & $33.30 \pm 0.52$ & $9.30 \pm 0.40$ \\
\hline & $\mathrm{CV} \%$ & 5.76 & 9.38 & 3.44 & 6.17 & 4.21 & 4.69 & 4.93 & 14.15 \\
\hline & Mean \pm SE & $69.37 \pm 2.29$ & $66.40 \pm 0.87$ & $25.84 \pm 0.35$ & $1.89 \pm 0.28$ & $116.40 \pm 5.09$ & $38.86 \pm 1.78$ & $32.65 \pm 0.97$ & $8.67 \pm 0.23$ \\
\hline \multirow{4}{*}{ II } & $\mathrm{CV} \%$ & 50.34 & 19.87 & 20.36 & 28.26 & 66.66 & 69.59 & 45.08 & 40.01 \\
\hline & $\mathrm{H}$ & 88.5 & 85.2 & 98.19 & 92.86 & 95.6 & 95.5 & 90.4 & 90.9 \\
\hline & $\Delta \mathrm{G}$ & 63.65 & 23.16 & 10.44 & 1.01 & 152.81 & 53.19 & 27.41 & 6.49 \\
\hline & $\Delta \mathrm{G} /$ Mean $(\%)$ & 91.77 & 34.88 & 40.42 & 53.64 & 131.28 & 136.87 & 83.95 & 74.88 \\
\hline \multirow[t]{2}{*}{$\mathrm{P}_{1}$ (Giza 95) } & Mean \pm SE & $70.90 \pm 0.75$ & $78.06 \pm 2.44$ & $31.33 \pm 0.18$ & $2.55 \pm 0.03$ & $79.43 \pm 1.61$ & $29.04 \pm 0.50$ & $36.68 \pm 0.53$ & $8.94 \pm 0.27$ \\
\hline & $\mathrm{CV} \%$ & 3.35 & 4.89 & 1.86 & 3.81 & 6.41 & 5.41 & 4.60 & 9.55 \\
\hline \multirow[t]{2}{*}{$\mathrm{P}_{2}($ Giza 80$)$} & Mean \pm SE & $75.13 \pm 0.55$ & $67.48 \pm 1.13$ & $21.50 \pm 0.18$ & $2.22 \pm 0.01$ & $55.40 \pm 1.22$ & $17.54 \pm 0.58$ & $33.88 \pm 0.75$ & $7.27 \pm 0.18$ \\
\hline & $\mathrm{CV} \%$ & 2.30 & 5.28 & 2.71 & 0.90 & 6.94 & 10.77 & 7.01 & 7.99 \\
\hline
\end{tabular}

$\Delta \mathrm{G}$; Expected genetic advance from selection $10 \%$ superior plants. 
The genotypic coefficient of variability among the ten selected families for number of balls/plant (Table 4) was large after two cycles of selection and sufficient for further cycles of selection in both populations. GCV estimates for number of balls/plant were 16.67 and $14.57 \%$ in populations I and II, respectively. The slight discrepancy between PCV and GCV caused high estimates of broad sense heritability for number of balls/plant and other correlated traits in both populations. It accounted 96.97 and $96.72 \%$ (NB/P), 92.46 and $94.75 \%$ (DFF), 96.81 and
94.83\% (EI), 96.08 and $95.24 \%(\mathrm{BW}), 97.37$ and $98.55 \%$ (SCY/P), 76.63 and $97.76 \%$ (LY/P), 96.71 and $96.76 \%$ (LP) and 95.97 and $97.83 \%$ (SI) in pop I and II, respectively (Table 4). Genetic coefficient of variation together with a heritability estimate would seem to give the pest picture of the genetic advance from selection (Burton, 1952; Sanghi et al., 1964). Similar results were obtained by Ahmed et al. (2006) and Khan et al. (2009) reported that broad sense heritability were high for number of bolls/plant, boll weight and seed cotton yield/plant.

Table 3. Simple correlation coefficients between each pairs of eight traits of the $F_{2}$-population $I$ (above diagonal) and $F_{2}$-population II (below diagonal).

\begin{tabular}{ccccccccc}
\hline Traits & DFF & EI & NB/P & BW & SCY/P & LY/P & LP & SI \\
\hline DFF & - & 0.014 & $-0.865^{* *}$ & -0.025 & $-0.289^{* *}$ & $-0.297^{* *}$ & $-0.142^{*}$ & 0.036 \\
EI & 0.024 & - & $-0.183^{* *}$ & 0.029 & $-0.160^{* *}$ & $-0.130^{*}$ & $0.212^{* *}$ & $-0.144^{*}$ \\
NB/P & $-0.287^{* *}$ & -0.088 & - & -0.076 & $0.933^{* *}$ & $0.905^{* *}$ & 0.052 & $0.252^{* *}$ \\
BW & $-0.137^{*}$ & $0.239^{* *}$ & $0.248^{* *}$ & - & $0.246^{* *}$ & $0.259^{* *}$ & $0.198^{* *}$ & $0.239^{* *}$ \\
SCY/P & $-0.296^{* *}$ & -0.023 & $0.945^{* *}$ & $0.485^{* *}$ & - & 0.979 & 0.112 & $0.322^{* *}$ \\
LY/P & $-0.299^{* *}$ & -0.006 & $0.937^{* *}$ & $0.493^{* *}$ & $0.993^{* *}$ & - & $0.268^{* *}$ & $0.306^{* *}$ \\
LP & -0.123 & 0.122 & $0.258^{* *}$ & $0.240^{* *}$ & $0.282^{* *}$ & $0.372^{* *}$ & - & 0.046 \\
SI & -0.122 & -0.112 & $0.336^{* *}$ & $0.237^{* *}$ & $0.343^{* *}$ & $0.313^{* *}$ & -0.097 & - \\
\hline
\end{tabular}

However, the realized heritability estimates were low and accounted for 37.06 and $63.50 \%$ in pop I and II, respectively. Estimates of the realized heritability were more reliable and accurate than broad sense heritability, except for the effect of genotypes by environmental interaction caused by growing of parent and offspring at two separate seasons. Mahdy et al. (2013) reported that the realized heritability and parent and offspring regression were 0.3890 and 0.0886 for pop I and 0.3946 and 0.1271 for pop I and pop II, respectively.

\subsubsection{Means of the selected families for selection criterion (number of bolls/plant) and the correlated traits}

In population I, mean values of number of bolls/plant of F4-selected families after two cycles of selection varied from 25.51 for family no. 216 to 46.70 for family no. 164 with an average of 40.66 bolls compared to 36.74 for Giza-90 and 35.68 for Giza-86. However, mean values of the correlated traits after two cycles of selection varied from 55.18 to 67.99 days, 68.45 to $80.78,1.89$ to $3.32 \mathrm{~g}$., 82.38 to $117.13 \mathrm{~g}$., 28.81 to 41.28 g., 34.09 to $36.69 \%$, and 7.07 to $9.82 \mathrm{~g}$. for days to first flower, earliness index, boll weight, seed cotton yield, lint yield/plant, lint percentage and seed index, respectively (Table 5). After two cycles of selection, average number of bolls/plant of F4-selected families in population II ranged from 29.55 (family no. 51) to 43.24 (family no. 60) with an average of 34.17 bolls compared to 30.90 for Giza-95 and 25.98 for Giza-80. Such wide variation in number of bolls/plant of the 10 selected families in the $\mathrm{F}_{4}$-generation in either population I or II encourage to do further cycles of selection, 
especially, when this variation accompanied with wide variation in all correlated traits. In addition, the average of the correlated traits i.e., days to first flower, earliness index, boll weight, seed cotton yield, lint yield/plant, lint percentage and seed index ranged from 55.14 to 71.75 days, 64.64 to $84.32,2.01$ to $2.98 \mathrm{~g}$., 64.94 to 106.43 g., 23.40 to 40.43 g., 35.37 to $40.15 \%$, and 6.06 to $10.42 \mathrm{~g}$., respectively (Table 6).

\subsubsection{Direct and indirect observed gain of the selected families for selection criterion and the correlated traits}

The average observed gain in number of bolls/plant was highly significant and recorded 10.67 and $12.41 \%$ from the better parent and the bulk sample, respectively. All the selected families exhibited highly significant highest in number of bolls/plant compared to the better parent and the bulk sample except the families no. 173 and 216 showed highly significant negative (Table 7). Two cycles of pedigree selection for increasing number of bolls/plant in population I caused favourable decrease in days to first flower by -6.40 and $-16.18 \%$ from the better parent and the bulk sample, respectively. Desirable increase in boll weight, seed cotton yield/plant, lint yield/plant and lint percentage over the better parent and the bulk sample accompanied pedigree selection for number of bolls/plant by 28.91 and $30.14 \%, 12.67$ and $17.44 \%, 18.20$ and $23.21 \%$ and 3.62 and $4.97 \%$, respectively. Undesirable decrease in seed index over the better parent and the bulk sample was resulted from pedigree selection for number of bolls/plant by -25.00 and $17.80 \%$, respectively (Table 7). The average observed gain in number of bolls/plant was highly significant and registered 10.58 and $17.26 \%$ from the better parent and the bulk sample, respectively. Some and most selected families illustrated highly significant highest in number of bolls/plant compared to the better parent and the bulk sample, respectively (Table 8). In population II, two cycles of pedigree selection for increasing number of bolls/plant caused undesirable decrease in earliness index by -1.07 and $1.11 \%$ from the better parent and the bulk sample, respectively. Desirable increase in boll weight, seed cotton yield/plant, lent yield/plant and lint percentage over the better parent and the bulk sample accompanied pedigree selection for number of bolls/plant by 0.83 and $2.54,6.20$ and 6.29, 11.92 and 14.23 and 5.37 and $7.47 \%$, respectively. Unfavorable increase in days to first flower over the better parent reached $6.29 \%$, but, respective desirable decrease was observed for this trait, which reached $-4.90 \%$ from the mean bulk sample (Table 8). Similar results were reported by Mahdy et al. (2001), ElOkkiah et al. (2008), Mahrous (2008) and Mahdy et al. (2009). Abuja et al. (2004) indicated that number of bolls/plant was the most important trait for selection of genotypes with high potential of seed cotton yield. Mahdy et al. (2013) indicated that selection criteria based on yield components rather than yield, where effective for simultaneous improving of yield and boll weight. Abd-El- Samee et al. (2020) reported that improving seed cotton yield/plant could be achieved by selection for number of bolls/plant, lint yield/plant and boll weight.

\section{Conclusion}

Selection for number of bolls/plant was accompanied by desirable decrease and in days to first flower in both populations. However, desirable increase for most correlated traits i.e., boll weight, seed cotton yield/plant, lint yield/plant and lint percentage in both populations. Two families; No. 96 and 178 in population I and family No. 60 in population II could be considered the best selected families resulted from selection for number of bolls/plant. Pedigree selection for number of bolls/plant was effective in isolating genotypes for high number of bolls. 
Table 4. Means squares, genotypic (GCV\%), phenotypic (PCV\%) coeffients of variabilty, broad sense heritabilty and realized for the selected families of number of balls/plant and correlated traits in $\mathrm{F}_{4}$ - generation for both populations (I and II).

\begin{tabular}{|c|c|c|c|c|c|c|c|c|c|c|}
\hline \multirow{2}{*}{ Populations } & \multirow{2}{*}{ S.O.V } & \multirow{2}{*}{ df } & \multirow{2}{*}{$\begin{array}{c}\text { Selection } \\
\text { creterion } \\
\text { NB/P }\end{array}$} & \multicolumn{7}{|c|}{ Correlated traits } \\
\hline & & & & DFF & EI & BW & $\mathrm{SCY} / \mathrm{P}$ & $\mathrm{LY} / \mathrm{P}$ & LP & SI \\
\hline \multirow{9}{*}{ I } & Reps & 2 & 1.67 & 1.16 & 24.73 & 0.05 & 1.13 & 0.10 & 3.07 & 0.05 \\
\hline & Genotypes & 12 & $116.29^{* *}$ & $93.17^{* *}$ & $29.67^{* *}$ & $0.41^{* *}$ & $350.67^{* *}$ & $2.30^{* * *}$ & $25.37^{* *}$ & $4.87^{* *}$ \\
\hline & Selected families & 9 & $142.32^{* *}$ & $41.93^{* *}$ & $36.35^{* *}$ & $0.51^{* *}$ & $308.86^{* *}$ & $1.84^{* *}$ & $30.74^{* * *}$ & $2.98^{* *}$ \\
\hline & Error (Genotypes) & 24 & 3.38 & 3.28 & 1.10 & 0.01 & 6.20 & 0.67 & 0.83 & 0.11 \\
\hline & Error (Selected families) & 18 & 4.31 & 3.16 & 1.16 & 0.02 & 8.13 & 0.43 & 1.01 & 0.12 \\
\hline & $\mathrm{GCV} \%$ & & 16.67 & 5.82 & 4.50 & 14.71 & 9.34 & 1.83 & 8.94 & 11.80 \\
\hline & PCV\% & & 16.95 & 6.06 & 4.58 & 15.07 & 9.47 & 2.07 & 9.08 & 12.04 \\
\hline & $\mathrm{H}_{\mathrm{b}} \%$ & & 96.97 & 92.46 & 96.81 & 96.08 & 97.37 & 76.63 & 96.71 & 95.97 \\
\hline & $\mathrm{h}^{2}$ & & 37.06 & - & - & - & - & - & - & - \\
\hline \multirow{9}{*}{ II } & Reps & 2 & 0.005 & 0.85 & 0.45 & 0.004 & 23.46 & 0.67 & 0.49 & 0.15 \\
\hline & Genotypes & 12 & $78.16^{* *}$ & $98.53^{* *}$ & $66.66^{* *}$ & $0.32^{* *}$ & $595.36^{* *}$ & $77.13^{* *}$ & $12.40^{* *}$ & $3.88^{* *}$ \\
\hline & Selected families & 9 & $76.84^{* *}$ & $83.75^{* *}$ & $88.22^{* *}$ & $0.42^{* *}$ & $775.47^{* *}$ & $99.91^{* *}$ & $10.79^{* *}$ & $5.08^{* *}$ \\
\hline & Error (Genotypes) & 24 & 2.79 & 4.30 & 4.54 & 0.01 & 11.01 & 2.09 & 0.44 & 0.14 \\
\hline & Error (Selected families) & 18 & 2.52 & 4.40 & 4.56 & 0.02 & 11.27 & 2.24 & 0.35 & 0.11 \\
\hline & GCV\% & & 14.57 & 7.72 & 6.89 & 14.88 & 20.47 & 18.72 & 4.96 & 14.91 \\
\hline & PCV\% & & 14.81 & 7.94 & 7.07 & 15.29 & 19.86 & 18.91 & 5.04 & 15.03 \\
\hline & $\mathrm{H}_{\mathrm{b}} \%$ & & 96.72 & 94.75 & 94.83 & 95.24 & 98.55 & 97.76 & 96.76 & 97.83 \\
\hline & $\mathrm{h}^{2}$ & & 36.50 & - & - & - & - & - & - & - \\
\hline
\end{tabular}

**: Significant at 0.01 level of probability. 
Table 5. Means of number of bolls/plant and the correlated response of the other traits of the selected families ( $\left.\mathrm{F}_{4}-\mathrm{generation}\right)$ for population I.

\begin{tabular}{|c|c|c|c|c|c|c|c|c|}
\hline \multirow{2}{*}{ Genotypes } & \multirow{2}{*}{$\begin{array}{c}\text { Selection } \\
\text { ceriteria } \\
\mathrm{NB} / \mathrm{P}\end{array}$} & \multicolumn{7}{|c|}{ Correlated response of the studied traits } \\
\hline & & DFF & EI & BW & $\mathrm{SCY} / \mathrm{P}$ & $\mathrm{LY} / \mathrm{P}$ & LP & SI \\
\hline 96 & 42.72 & 55.18 & 77.97 & 3.32 & 117.13 & 39.91 & 34.09 & 7.84 \\
\hline 131 & 42.69 & 62.83 & 77.20 & 2.54 & 98.65 & 36.18 & 36.69 & 7.07 \\
\hline 164 & 46.70 & 63.23 & 73.77 & 2.57 & 113.08 & 39.33 & 34.78 & 9.43 \\
\hline 169 & 46.01 & 62.85 & 73.04 & 2.56 & 109.72 & 39.42 & 35.92 & 7.51 \\
\hline 173 & 30.96 & 57.12 & 76.08 & 1.89 & 82.38 & 28.81 & 34.96 & 7.57 \\
\hline 178 & 41.85 & 60.00 & 80.78 & 3.13 & 106.03 & 37.15 & 35.04 & 9.82 \\
\hline 216 & 25.51 & 64.57 & 79.35 & 2.74 & 109.84 & 38.15 & 34.76 & 8.05 \\
\hline 238 & 43.50 & 67.99 & 76.00 & 3.19 & 114.52 & 41.28 & 36.05 & 9.54 \\
\hline 257 & 41.60 & 63.42 & 76.68 & 2.57 & 106.94 & 37.01 & 34.64 & 7.91 \\
\hline 259 & 45.07 & 59.79 & 68.45 & 2.67 & 113.19 & 40.13 & 35.46 & 7.42 \\
\hline Average & 40.66 & 61.70 & 75.93 & 2.72 & 107.15 & 37.74 & 35.24 & 8.22 \\
\hline Giza-90 & 36.74 & 73.90 & 75.94 & 2.11 & 95.1 & 31.93 & 33.58 & 10.96 \\
\hline Giza-86 & 35.68 & 65.92 & 72.17 & 2.02 & 86.5 & 29.42 & 34.01 & 9.88 \\
\hline Bulk's mean & 36.17 & 73.61 & 72.93 & 2.09 & 91.24 & 30.63 & 33.57 & 10.00 \\
\hline RL.S.D 0.05 & 4.15 & 4.02 & 1.35 & 0.01 & 7.61 & 1.02 & 1.02 & 0.13 \\
\hline RL.S.D 0.01 & 5.50 & 5.34 & 1.79 & 0.02 & 10.09 & 1.42 & 1.35 & 0.18 \\
\hline R. L.S.D ${ }_{0.05}$ Average & 2.04 & 2.02 & 1.16 & 0.12 & 2.78 & 1.14 & 1.01 & 0.37 \\
\hline R. L.S.D ${ }_{0.01}$ Average & 2.71 & 2.68 & 1.54 & 0.15 & 3.68 & 1.59 & 1.34 & 0.49 \\
\hline
\end{tabular}


Table 6. Means of number of balls/plant and the correlated response of the other traits of the selected families ( $\left.\mathrm{F}_{4}-\mathrm{generation}\right)$ for population II.

\begin{tabular}{|c|c|c|c|c|c|c|c|c|}
\hline \multirow{2}{*}{ Genotypes } & \multirow{2}{*}{$\begin{array}{c}\text { Selection } \\
\text { ceriteria } \\
\mathrm{NB} / \mathrm{P}\end{array}$} & \multicolumn{7}{|c|}{ Correlated response of the studied traits } \\
\hline & & DFF & EI & BW & $\mathrm{SCY} / \mathrm{P}$ & $\mathrm{LY} / \mathrm{P}$ & LP & SI \\
\hline 51 & 29.55 & 59.49 & 70.97 & 2.98 & 92.84 & 31.50 & 39.98 & 9.58 \\
\hline 60 & 43.24 & 65.93 & 78.08 & 2.46 & 106.43 & 40.43 & 35.37 & 8.79 \\
\hline 62 & 32.72 & 71.17 & 80.78 & 2.01 & 65.88 & 24.40 & 36.55 & 7.65 \\
\hline 75 & 32.43 & 67.08 & 76.96 & 2.74 & 72.50 & 28.19 & 40.15 & 7.68 \\
\hline 96 & 30.67 & 55.14 & 64.64 & 2.90 & 104.72 & 37.11 & 39.35 & 7.95 \\
\hline 108 & 29.74 & 67.80 & 79.42 & 2.19 & 64.94 & 23.67 & 36.45 & 9.28 \\
\hline 127 & 43.16 & 67.68 & 76.90 & 2.09 & 90.13 & 34.75 & 36.62 & 6.06 \\
\hline 181 & 32.52 & 71.75 & 78.19 & 2.70 & 71.18 & 26.55 & 35.79 & 9.73 \\
\hline 192 & 35.57 & 69.63 & 76.51 & 2.06 & 73.34 & 26.95 & 36.74 & 10.42 \\
\hline 202 & 32.06 & 69.69 & 84.32 & 2.11 & 67.60 & 25.57 & 39.80 & 9.36 \\
\hline Average & 34.17 & 66.54 & 76.68 & 2.42 & 80.96 & 30.51 & 37.68 & 8.65 \\
\hline Giza-95 & 30.90 & 77.51 & 77.72 & 2.40 & 76.23 & 27.26 & 35.76 & 9.12 \\
\hline Giza-80 & 25.98 & 62.60 & 77.51 & 2.26 & 72.62 & 24.90 & 34.29 & 8.47 \\
\hline Bulk's mean & 29.14 & 69.97 & 77.54 & 2.36 & 76.17 & 26.71 & 35.06 & 8.55 \\
\hline RL.S.D 0.05 & 3.42 & 5.27 & 5.78 & 0.01 & 13.51 & 2.56 & 0.54 & 0.17 \\
\hline RL.S.D 0.01 & 4.54 & 6.99 & 7.69 & 0.02 & 17.91 & 3.40 & 0.72 & 0.23 \\
\hline R. L.S.D ${ }_{0.05}$ Average & 1.86 & 2.32 & 2.46 & 0.12 & 4.05 & 1.62 & 0.74 & 0.40 \\
\hline R. L.S.D ${ }_{0.01}$ Average & 2.46 & 3.07 & 3.28 & 0.15 & 5.37 & 2.15 & 0.98 & 0.54 \\
\hline
\end{tabular}


Table 7. The observed direct gain and correlated response as percentage from the better parent and the bulk sample of the selected families $\left(\mathrm{F}_{4}-\right.$ generation) for population $\mathrm{I}$.

\begin{tabular}{|c|c|c|c|c|c|c|c|c|c|}
\hline \multirow{2}{*}{ Item } & \multirow[t]{2}{*}{ Families no. } & \multirow{2}{*}{$\begin{array}{c}\text { Selection ceriterion } \\
\text { NB/P }\end{array}$} & \multicolumn{7}{|c|}{ Correlated response of the studied traits } \\
\hline & & & DFF & EI & BW & $\mathrm{SCY} / \mathrm{P}$ & $\mathrm{LY} / \mathrm{P}$ & LP & SI \\
\hline \multirow{11}{*}{ Better parent } & 96 & $16.28^{* *}$ & $-16.29^{* *}$ & $2.67^{*}$ & $57.35^{* *}$ & $23.17^{* *}$ & $24.99^{* *}$ & 0.24 & $-28.47^{* * *}$ \\
\hline & 131 & $16.19^{* *}$ & $-4.69^{*}$ & 1.66 & $20.38^{* *}$ & 3.73 & $13.31^{* *}$ & $7.88^{* * *}$ & $-35.49^{* *}$ \\
\hline & 164 & $27.11^{* *}$ & -4.08 & $-2.86^{*}$ & $21.80^{* * *}$ & $18.91^{* *}$ & $23.18^{* * *}$ & 2.26 & $-13.96^{* *}$ \\
\hline & 169 & $25.23^{* *}$ & $-4.66^{*}$ & -3.82 & $21.33^{* *}$ & $15.37^{* *}$ & $23.46^{* *}$ & $5.62^{*}$ & $-31.48^{* *}$ \\
\hline & 173 & $-15.73^{* *}$ & $-13.35^{* *}$ & 0.18 & $-10.43^{*}$ & $-13.38^{* *}$ & $-9.77^{* *}$ & 2.79 & $-30.93^{* *}$ \\
\hline & 178 & $13.91^{* *}$ & $-8.98^{* *}$ & $6.37^{* *}$ & $48.34^{* *}$ & $11.49^{* *}$ & $16.35^{* *}$ & 3.03 & $-10.40^{* *}$ \\
\hline & 216 & $-30.57^{* *}$ & -2.05 & $4.49^{* *}$ & $29.86^{* *}$ & $15.50^{* * *}$ & $19.48^{* *}$ & 2.21 & $-26.55^{* *}$ \\
\hline & 238 & $18.40^{* *}$ & 3.14 & 0.08 & $51.18^{* *}$ & $20.42^{* *}$ & $29.28^{* *}$ & $6.00^{* *}$ & $-12.96^{* * *}$ \\
\hline & 257 & $13.23^{* *}$ & -3.79 & 0.97 & $21.80^{* * *}$ & $12.45^{* *}$ & $15.91^{* *}$ & 1.85 & $-27.83^{* *}$ \\
\hline & 259 & $22.67^{* *}$ & $-9.30^{* *}$ & $-9.86^{* *}$ & $26.54^{* *}$ & $19.02^{* *}$ & $25.68^{* * *}$ & 4.26 & $-32.30^{* * *}$ \\
\hline & Average & $10.67^{* *}$ & $-6.40^{* *}$ & -0.01 & $28.91^{* *}$ & $12.67^{* * *}$ & $18.20^{* *}$ & $3.62^{*}$ & $-25.00^{* *}$ \\
\hline \multirow{11}{*}{ Bulk } & 96 & $18.11^{* *}$ & $-25.04^{* *}$ & $6.91^{* *}$ & $58.85^{* *}$ & $28.38^{* *}$ & $30.30^{* *}$ & 1.55 & $-21.60^{* *}$ \\
\hline & 131 & $18.03^{* *}$ & $-14.64^{* *}$ & $5.85^{* *}$ & $21.53^{* *}$ & $8.12^{* *}$ & $18.12^{* *}$ & $9.29^{* *}$ & $-29.30^{* *}$ \\
\hline & 164 & $29.11^{* *}$ & $-14.10^{* *}$ & 1.15 & $22.97^{* *}$ & $23.94^{* *}$ & $28.40^{* *}$ & 3.60 & $-5.70^{*}$ \\
\hline & 169 & $27.20^{* *}$ & $-14.62^{* *}$ & 0.15 & $22.49^{* *}$ & $20.25^{* *}$ & $28.70^{* * *}$ & $7.00^{* *}$ & $-24.90^{* * *}$ \\
\hline & 173 & $-14.40^{* *}$ & $-22.40^{* *}$ & $4.32^{* *}$ & -9.57 & $-9.71^{* *}$ & $-5.94^{*}$ & 4.14 & $-24.30^{* * *}$ \\
\hline & 178 & $15.70^{* *}$ & $-18.49^{* *}$ & $10.76^{* *}$ & $49.76^{* *}$ & $16.21^{* *}$ & $21.29^{* *}$ & 4.38 & -1.80 \\
\hline & 216 & $-29.47^{* *}$ & $-12.28^{* *}$ & $8.80^{* *}$ & $31.10^{* *}$ & $20.39^{* *}$ & $24.55^{* *}$ & 3.54 & $-19.50^{* * *}$ \\
\hline & 238 & $20.27^{* *}$ & $-7.63^{* *}$ & $4.21^{* *}$ & $52.63^{* *}$ & $25.52^{* * *}$ & $34.77^{* *}$ & $7.39^{* *}$ & -4.60 \\
\hline & 257 & $15.01^{* *}$ & $-13.84^{* *}$ & $5.14^{* *}$ & $22.97^{* *}$ & $17.21^{* *}$ & $20.83^{* * *}$ & 3.19 & $-20.90^{* * *}$ \\
\hline & 259 & $24.61^{* *}$ & $-18.77^{* *}$ & $-6.14^{* *}$ & $27.75^{* *}$ & $24.06^{* *}$ & $31.02^{* * *}$ & $5.63^{*}$ & $-25.80^{* *}$ \\
\hline & Average & $12.41^{* *}$ & $-16.18^{* *}$ & $4.11^{* *}$ & $30.14^{* *}$ & $17.44^{* *}$ & $23.21^{* *}$ & $4.97^{* *}$ & $-17.80^{* *}$ \\
\hline L.S.D 0.05 & & 3.10 & 3.05 & 1.75 & 0.21 & 4.19 & 1.38 & 1.53 & 0.54 \\
\hline L.S.D 0.01 & & 4.20 & 4.14 & 2.38 & 0.28 & 5.68 & 1.87 & 2.07 & 0.73 \\
\hline L.S.D ${ }_{0.05}$ Average & & 2.29 & 2.27 & 1.30 & 0.13 & 3.12 & 1.03 & 1.14 & 0.41 \\
\hline L.S.D ${ }_{0.01}$ Average & & 3.10 & 3.08 & 1.76 & 0.18 & 4.22 & 1.40 & 1.54 & 0.56 \\
\hline
\end{tabular}

${ }^{*}, * *$ : Significant at 0.05 and 0.01 levels of probability, respectively. 
Table 8. The observed direct gain and correlated response as percentage from the bulk sample of the selected families $\left(\mathrm{F}_{4}-\right.$ generation) from single seed descent method for population II.

\begin{tabular}{|c|c|c|c|c|c|c|c|c|c|}
\hline \multirow{2}{*}{ Item } & \multirow[t]{2}{*}{ Families no. } & \multirow{2}{*}{$\begin{array}{c}\text { Selection ceriterion } \\
\text { NOB/P }\end{array}$} & \multicolumn{7}{|c|}{ Correlated response of the studied traits } \\
\hline & & & DFF & EI & $\mathrm{BW}$ & $\mathrm{SCY} / \mathrm{P}$ & $\mathrm{LY} / \mathrm{P}$ & LP & SI \\
\hline \multirow{11}{*}{ Better parent } & 51 & -4.37 & -4.97 & $-8.44^{* *}$ & $24.17^{* *}$ & $21.79^{* *}$ & $15.55^{* *}$ & $11.80^{* *}$ & 5.04 \\
\hline & 60 & $39.94^{* *}$ & 5.32 & 0.74 & 2.50 & $39.62^{* *}$ & $48.31^{* *}$ & -1.09 & -3.62 \\
\hline & 62 & 5.89 & $13.69^{* *}$ & 4.22 & $-16.25^{* *}$ & $-13.58^{* *}$ & $-10.49^{*}$ & 2.21 & $-16.12^{* *}$ \\
\hline & 75 & 4.95 & $7.16^{*}$ & -0.71 & $14.17^{* *}$ & -4.89 & 3.41 & $12.28^{* *}$ & $-15.79^{* *}$ \\
\hline & 96 & -0.74 & $-11.92^{* *}$ & $-16.60^{* *}$ & $20.83^{* *}$ & $37.37^{* *}$ & $36.13^{* *}$ & $10.04^{* *}$ & $-12.83^{* *}$ \\
\hline & 108 & -3.75 & $8.31^{* *}$ & 2.46 & $-8.75^{*}$ & $-14.81^{* *}$ & $-13.17^{* *}$ & 1.93 & 1.75 \\
\hline & 127 & $39.68^{* *}$ & $8.12^{* * *}$ & -0.79 & $-12.92^{* *}$ & $18.23^{* *}$ & $27.48^{* * *}$ & 2.40 & $-33.55^{* * *}$ \\
\hline & 181 & 5.24 & $14.62^{* *}$ & 0.88 & $12.50^{* *}$ & -6.62 & -2.60 & 0.08 & 6.69 \\
\hline & 192 & $15.11^{* *}$ & $11.23^{* *}$ & -1.29 & $-14.17^{* *}$ & -3.79 & -1.14 & 2.74 & $14.25^{* *}$ \\
\hline & 202 & 3.75 & $11.33^{* *}$ & $8.79^{* *}$ & $-12.08^{* *}$ & $-11.32^{* *}$ & -6.20 & $11.30^{* *}$ & 2.63 \\
\hline & Average & $10.58^{* *}$ & $6.29^{* * *}$ & -1.07 & 0.83 & $6.20^{*}$ & $11.92^{* *}$ & $5.37^{* *}$ & $-5.15^{*}$ \\
\hline \multirow{11}{*}{ Bulk } & 51 & 1.41 & $-14.98^{* *}$ & $-8.47^{* *}$ & $26.27^{* *}$ & $21.89^{* *}$ & $17.93^{* *}$ & $14.03^{* *}$ & $12.05^{* *}$ \\
\hline & 60 & $48.39^{* *}$ & $-5.77^{*}$ & 0.70 & 4.24 & $39.73^{* *}$ & $51.37^{* *}$ & 0.88 & 2.81 \\
\hline & 62 & $12.29^{*}$ & 1.72 & 4.18 & $-14.83^{* *}$ & $-13.51^{* *}$ & -8.65 & 4.25 & -10.53 \\
\hline & 75 & $11.29^{*}$ & -4.13 & -0.75 & $16.10^{* * *}$ & -4.82 & 5.54 & $14.52^{* *}$ & $-10.18^{* *}$ \\
\hline & 96 & 5.25 & $-21.19^{* *}$ & $-16.64^{* *}$ & $22.88^{* *}$ & $37.48^{* *}$ & $38.94^{* *}$ & $12.24^{* *}$ & -7.02 \\
\hline & 108 & 2.06 & -3.10 & 2.42 & -7.20 & $-14.74^{* *}$ & $-11.38^{*}$ & 3.96 & $8.54^{*}$ \\
\hline & 127 & $48.11^{* *}$ & -3.27 & -0.83 & $-11.44^{*}$ & $18.33^{* *}$ & $30.10^{* *}$ & 4.45 & $-29.12^{* *}$ \\
\hline & 181 & $11.60^{*}$ & 2.54 & 0.84 & $14.41^{* *}$ & -6.55 & -0.60 & 2.08 & $13.80^{* *}$ \\
\hline & 192 & $22.07^{* *}$ & -0.49 & -1.33 & $-12.71^{* *}$ & -3.72 & 0.90 & 4.79 & $21.87^{* *}$ \\
\hline & 202 & $10.02^{*}$ & -0.40 & $8.74^{* * *}$ & $-10.59^{*}$ & $-11.25^{* *}$ & -4.27 & $13.52^{* *}$ & $9.47^{*}$ \\
\hline & Average & $17.26^{* *}$ & $-4.90^{*}$ & -1.11 & 2.54 & $6.29^{*}$ & $14.23^{* *}$ & $7.47^{* *}$ & 1.17 \\
\hline L.S.D 0.05 & & 2.81 & 3.49 & 3.59 & 0.21 & 5.59 & 2.44 & 1.78 & 0.62 \\
\hline L.S.D 0.01 & & 3.80 & 4.73 & 4.87 & 0.28 & 7.58 & 3.30 & 2.41 & 0.84 \\
\hline L.S.D ${ }_{0.05}$ Average & & 2.08 & 2.60 & 2.66 & 0.13 & 4.54 & 1.82 & 0.83 & 0.45 \\
\hline L.S.D ${ }_{0.01}$ Average & & 2.82 & 3.52 & 3.61 & 0.18 & 6.15 & 2.46 & 1.12 & 0.62 \\
\hline
\end{tabular}

*, **: Significant at 0.05 and 0.01 levels of probability, respectively 


\section{References}

Abd El Sameea, A.A., Ibrahim, M.M., Ahmad, M.SH. and EL-Tahan, S. A. (2020) 'Pedigree selection for lint yield in two segregation populations of Egyptian cotton (Gossypium barbadense L.)' World J Agri \& Soil Sci., 5(4): pp. $1-8$.

Ahmed, H.M., Kandhro, M.M.S., Laghari and Abro, S. (2006) 'Heritability and genetic advance as selection indicator for improvement in cotton (Gossypium hirsutum L.)’ J. Bio. Sci., 6: pp. 96-99.

Ahuja, S. L., Monga, D., Tuteja, O.P., Verma, S.K., Dhayal, L.S. and Yagya, D. (2004) 'Association and path analysis in the selection made from colour linted (Gossypium hirsutum L.) cotton germplasm' J. Cott. Res. Rev.,18(2): pp. 137-140.

Ahsan, M.Z., Majidano, M.S., Bhutto, H., Soomro, A., Panhwar, F.H., Channa, A., and Sial, K.B. (2015) 'Genetic variability, coefficient of variance, heritability and genetic advance some accessions (Gossypium hirsutum L.)' Journal of Agricultural Science, 7(2): $147-151$.

Alkuddsi, Y., Patil, S.S., Manjula, S.M., Patil, B.C., Nadaf, H.L. and Nandihali, B.S. (2013) 'Genetic variability studies in segregating generation of Gossypium barbadense lines in cotton' Plant Genetics and trait, 4(17): pp. 90 - 94.

Al-Jibouri, H.A., Miller, P.A. and Robinson, H.F. (1958) 'Genotypic and environmental variance and covariance in an upland cotton cross of interspecific origin' Agron. J. Sci., pp. 633-636.
Basbag, S. and Oktay, G. (2004) 'Investigations on the heritability of seed cotton yield, yield components and technological characters in cotton (Gossypium hirsutum L.)' Pakistan Journal of Biological Sciences, DOI:10.3923/pjbs. 1390.1393.

Burton, G.W. (1952) 'Quantitative inheritance in grasses' $6^{\text {th }}$ Internat. Grassland Cong. Proc., 1: pp. 227-238.

El-Rawi, K., and Khalafalla, A.M. (1980) 'Design and Analysis of Agricultural Experiments' El Mousel Univ., Iraq, 1.

El-Zanaty, A.M., Salem, K.F.M. and Esmail, R.M. (2011) 'Detection of Genetic Diversity in Egyptian Cotton (Gossypium barbadense L.) Varieties Using RAPD Markers and Morphological Traits' Journal of American Science, 7(12): pp. $1107-1115$.

EL-Okkiah A.F.H., Kassem, M.M., Sary, G.A. and EL-Lawendey, M.M. (2008) 'Improving lint yield and its components in early segregating generations of Giza $45 \times$ Giza 75 cotton cross' Egypt. J. Agric. Res., 86: pp. 631-641.

FAOSTAT (2019) 'GEWS-Global information and Early Warning System, (http://www.fao.org/giews/countrybri ef/country.jsp/?code=EGY.

Khan, N.U., Hassan, G., Khan, I.A. and Ahmad, W. (2009) 'Genetic variability and heritability in upland cotton' Pak. J. Bot., 41: pp. 1695-1705.

Mahdy, E.E., Ismail, A.A. Awad, H.Y. and Mohamed, A.A. (2001) 'The relative 
merits of breeding and modified recurrent selection in improving seed cotton yield in two segregating populations of Egyptian cotton (G. barbadense L.)' The $2^{\text {nd }}$ Plant Breed. Conf. Oct. 2, pp. 61-79.

Mahdy, E.E., Hemaida, G.M.K., Abd ElMotagally, F.M.F. and Mostafa, A. (2009) 'Response to selection for yield under late sowing date in two populations of Egyptian cotton' Assiut J. of Agric. Sci., 40(Special Issue): pp. 1-25

Mahdy, E. E, Hassaballa, E.A., Mohamed, A.A. and Aly, A.M. (2013) 'Pedigree selection for number of bolls/plant in two populations of Egyptian cotton under late planting conditions' Egypt. J. of Appl. Sci., 28(4): pp. 255-270.

Mahrous, H. and Soliman, A.M. (2017) 'Pedigree selection for seed cotton yield and boll weight in two segregating populations of Egyptian cotton' Egypt. J. of Appl. Sci., 32(12 B) pp. 495 - 508.

Mahrous, H. (2018) 'Breeding for high yielding ability and heat tolerance in Egyptian cotton. Egypt' J. Plant Breed., 22(3): pp. 561-577.
Mahrous, H. (2008) 'Selection for earliness and lint yield in early and late plantings in some populations of Egyptian cotton' $\mathrm{Ph}$. D. Thesis, Assiut Univ., Egypt.

Okaz, A.M.A., Ahmad, M.S.H. and Ahmed, B.H. (2017) 'Response to selection using two selection methods in two populations of Egyptian cotton (Gossypium barbadense L.)' Assiut J. Agric. Sci., 48(3): pp. 1-21.

Soomro, Z. A., Kumbhar, M.B., Larik, A.S., Imran, M. and Brohi, S.A. (2010) 'Heritability and selection response in segregating generations of upland cotton' Pakistan J. Agric. Res., 23: pp. 1-2.

Sanghi, A.K., Bhatnagar, M.P. and Sharm, S.K. (1964) 'Genotypic and phenotypic variability in yield and other quantitative character in guar' Indian J. Gent. Plant Breed., 29: pp. $164-164$.

Snedecor, G.W. and Cochran, W.G. (1980) 'Statistical methods' Seven Edition. The Iowa State University Press. Ames. Iowa. USA.

Walker, J.T. (1960) 'The use of a selection index technique in the analysis of progeny row data' Emp. Cott. Gr. Rev., 37: pp. 81-107. 